\title{
Políticas contemporâneas de formação de alfabetizadores no Brasil: entre a potencialização dos desempenhos e a gestão pedagógica das inovações
}

\section{Contemporary policies of literacy teacher training in Brazil: between enhancement of performances and pedagogical management of innovations}

\section{Políticas contemporáneas de formación de los profesores alfabetizadores en Brasil: entre la potenciación de actuaciones y gestión pedagógicas de las innovaciones}

\author{
Roberto Rafael Dias da Silva* \\ Rodrigo Saballa de Carvalho** \\ Rodrigo Manoel Dias da Silva**
}

\begin{abstract}
Resumo: O presente artigo examina as atuais políticas de formação de professores alfabetizadores no Brasil, materializadas recentemente no Pacto Nacional pela Alfabetização na Idade Certa (PNAIC), e visa analisar as estratégias políticas que podem ser visibilizadas em seu processo de implementação. Situando-as nos cenários de reforma educacional, em suas modalidades de regulação e dominação política, reconhece-se que as concepções de formação de professores colocadas em ação são potencializadas por meio de modos de individualização dos percursos formativos, ao mesmo tempo em que intensificam as formas de gestão governamental da ação dos professores alfabetizadores. Conclui-se que tal intervenção formativa aposta nos modelos de avaliação de larga escala como objetivo estratégico e produz esforços na direção de uma docência em inovação permanente, apropriada para os regimes de inspiração neoliberal, predominantes nas políticas de escolarização mobilizadas no país. Palavras-chave: Política educacional. Formação de professores. Alfabetização.
\end{abstract}

Abstract: This paper examines the current policies of literacy teacher training in Brazil, recently materialized in the Pacto Nacional pela Alfabetização na Idade Certa

\footnotetext{
* Professor da Universidade Federal da Fronteira Sul (UFFS). E-mail: <robertoddsilva@yahoo.com.br>

** Professor da Universidade Federal da Fronteira Sul (UFFS). E-mail: <rsaballa@terra.com.br>

*** Professor da Universidade Federal da Fronteira Sul (UFFS). E-mail: <rodrigo@uffs.edu.br>
} 
(PNAIC - National Pact for Literacy at the Right Age), and it aims to analyze the political strategies that can be visualized in its implementation process. Placing them in scenarios of educational reform in their modes of regulation and political domination, we acknowledge that the conceptions of teacher education put into action are enhanced through the modes of educational path individualization, at the same time that they intensify the ways of government management of literacy teacher action. We conclude that such educational intervention bets on models of large-scale assessment as strategic goal and produces efforts towards a permanent innovation in teaching, appropriate to the neoliberal regimes, predominant in the education policies mobilized in the country. Keywords: Education policy. Teacher education. Literacy.

Resumen: Este artículo examina las políticas actuales de la formación de profesores de alfabetización en Brasil, recientemente se materializó en el Pacto Nacional por la Alfabetización en la Edad Apropiada - PNAIC, con objetivo de analizar las estrategias políticas que pueden ser visualizadas en su proceso de implementación. Situando en los contextos de la reforma educativa, en sus modalidades de regulación y la dominación política, los autores reconocen que las concepciones de la formación del profesorado puestas en acción son reforzadas por medio de la individualización de los caminos formativos, al mismo tiempo intensificar las formas la gestión gubernamental de la acción de los profesores alfabetizadores. Concluyen que tal intervención formativa apuesta en los modelos de evaluación en gran escala como objetivo estratégico y produce esfuerzos en dirección de una docencia en innovación permanente, apropiada para los regímenes de inspiración neoliberales, predominantemente en las políticas de educación en nuestro país.

Palabras clave: Política educativa. Formación del profesorado. Alfabetización.

Estabelecendo um olhar mais atento sobre as políticas de escolarização colocadas em ação nas últimas duas décadas, em nosso país, precisamos reconhecer a existência de um conjunto de novos investimentos na figura do professor. $\mathrm{Na}$ medida em que, em tempos anteriores, se notava uma priorização nas mudanças de ordem metodológica ou mesmo, mais recentemente, na implementação de reformas curriculares, o início do século XXI emergiu trazendo novos delineamentos. Em uma perspectiva histórica, Nóvoa (2009) argumenta que, em nosso tempo, os professores ingressam novamente como alvo da agenda educacional, posicionando-se "[...] não só na promoção das aprendizagens, mas também na construção de processos de inclusão que respondam aos desafios da diversidade e no desenvolvimento de métodos apropriados de utilização das novas tecnologias" (NÓVOA, 2009, p. 13). Entretanto, uma ressalva precisa ser feita no início desta composição analítica: não foram os próprios professores que potencializaram as pautas pedagógicas emergentes neste século. 
$\mathrm{Na}$ análise desenvolvida pelo historiador português, pelo menos dois grupos intervieram na fabricação deste consenso acerca dos percursos da escola contemporânea. Os discursos sobre a nova docência foram desencadeados tanto por comunidades e redes de especialistas de instituições de pesquisa e universidades, quanto pela atividade de consultores de organizações internacionais. Evidencia-se, então, uma "inflação discursiva" sobre a docência, ao mesmo tempo em que os professores "[...] viram o seu território profissional e simbólico ocupado por outros grupos" (NÓVOA, 2009, p. 16). Dentre os consensos produzidos nessas condições, as perspectivas de aprendizagem permanente têm adquirido intensa visibilidade, não percebidas como um direito ou uma necessidade profissional, mas como um tipo de constrangimento (NÓVOA, 2009).

Acerca dessas condições, notamos a produção de, pelo menos, dois cenários. O primeiro diz respeito a uma proliferação de cursos, seminários, fóruns, revistas e espaços digitais que caracterizam " [...] o atual 'mercado da formação' sempre alimentado por um sentimento de 'desactualização' dos professores” (NÓVOA, 2009 , p. 24, grifo do autor). Por outro lado, outro cenário sinaliza uma ampliação excessiva das missões da instituição escolar, na qual novas tarefas ingressam periodicamente em sua pauta, constituindo em um "transbordamento da escola" (NÓVOA, 2009, p. 26). Paradoxalmente, sob tais condições, ao mesmo tempo, o professor é interpelado a sentir-se desatualizado e a ingressar no mercado da formação.

Ao considerarmos o diagnóstico produzido por Nóvoa, direcionaremos nossa preocupação analítica para os recentes programas de formação de professores alfabetizadores em curso no Brasil. Ainda que decorrentes das estratégias de expansão do Ensino Fundamental, multiplicaram-se programas governamentais destinados a regular as práticas profissionais dos docentes que atuam nos níveis de alfabetização. São conhecidos programas como o Pro-Letramento e, recentemente, o Pacto Nacional pela Alfabetização na Idade Certa (PNAIC), programas estes que anunciam compromissos estatais pelo cumprimento de metas e de indicadores voltados à alfabetização no campo da língua materna e matemática ${ }^{1}$. Afora outras considerações, tais programas de intervenção pedagógica centralizam a consecução de objetivos e de resultados na figura da docência. O professor, enquanto ator estratégico do processo de alfabetização, assume responsabilidades específicas em formar seus estudantes e, por conseguinte, formar-se. Ou seja, investe-se em sua formação com a finalidade de potencializar seus desempenhos, qualificar seus resultados e estimular suas capacidades inovadoras em uma nova

\footnotetext{
${ }^{1}$ Em relação aos programas citados, cabe esclarecer que o Pró-letramento teve uma maior abrangência que o Pacto Nacional pela Alfabetização na Idade Certa (PNAIC), pois atendeu os professores dos anos iniciais do Ensino Fundamental. Por outro lado, o PNAIC atendeu somente os professores do Ciclo de alfabetização $\left(1^{\circ}\right.$ ao $3^{\circ}$ ano do Ensino Fundamental). Em 2015, a proposta do PNAIC era fazer uma articulação com todas as áreas do conhecimento.
} 
arquitetura institucional. Essa hipótese será mais bem desenvolvida na sequência desta elaboração.

\section{Cenários de reforma nas políticas de escolarização: uma revisão}

A partir de meados da década de 1990, um conjunto de novas racionalidades políticas começa a redefinir o papel do Estado no que tange às políticas de escolarização (LUNDGREN, 2013; POPKEWITZ, 2013). Uma das estratégias governamentais que adquiriram maior visibilidade e intensidade foi o desenvolvimento de avaliações de larga escala. De acordo com Lundgren (2013), o desenvolvimento de técnicas de medição por meio de provas começou a desencadear-se no século XIX. É exemplar, nessa direção, o sistema de provas promovido na Inglaterra, a partir de 1862, no qual se buscava articular o apoio financeiro às escolas aos resultados obtidos (LUNDGREN, 2013). Paralelamente a esse sistema, ampliavam-se os sistemas avaliativos vinculados à ciência psicológica, sendo os avanços teóricos de Thorndike bastante significativos.

Em torno desses desenvolvimentos, o tema da avaliação adquire ampla aceitação na comunidade educacional, ao ponto que na educação moderna ocupe uma dimensão central. Em um exercício de historicização, Lundgren (2013, p. 17) sugere que "[...] as técnicas de avaliação foram desenvolvidas como base ao conteúdo curricular". Ainda que suas raízes estejam no século XIX, conforme sinalizamos anteriormente, será na segunda metade do século XX, por intermédio do impulso produzido pela Guerra Fria, que emergirão as avaliações internacionais para a investigação comparada. No ano de 1962, após o lançamento do Sputnik, foi criada nos Estados Unidos a Associação Internacional para Avaliação do Rendimento Educativo - IEA (LUNDGREN, 2013).

Os interesses políticos e econômicos, sob esse entendimento, produziam repercussão nos interesses de investigação. A Teoria do Capital Humano, inspirada nos escritos de Schultz, procurava correlacionar os investimentos em educação ao crescimento econômico dos países. Nesse cenário, a regulação das políticas de escolarização é articulada com a medição, adquirindo centralidade às noções de eficiência e produtividade. Nos anos de 1980, com as mudanças na conjuntura internacional e o advento da globalização, modificam-se as formas de governo, ora privilegiando a descentralização, ora evidenciando o melhoramento dos sistemas de ensino. De acordo com Lundgren (2013), nessas condições, emergem como solução as estratégias da nova gestão pública. Em suas palavras, “[...] a educação converteu-se, portanto, em um cenário para consultores com o claro objetivo de aumentar a eficiência e reestruturar a gestão" (LUNDGREN, 2013, p. 20).

A partir da década de 1990, com um novo consenso internacional em torno da sociedade do conhecimento, novas forças políticas começam a operar, 
produzindo outros sistemas de governança (LUNDGREN, 2013). A prestação de contas, associada à individualização das responsabilidades, evidencia a mobilização e a consolidação de uma nova pauta internacional.

Em resumo, as mudanças na produção e na economia criaram uma pressão sobre o desenvolvimento de uma sociedade do bem-estar em expansão. Os movimentos em torno da descentralização e da privatização podem ser interpretados como duas formas de resolver os problemas. Ambas as soluções exigem mudanças nos programas e nas avaliações. (LUNDGREN, 2013, p. 24).

No contexto da emergente sociedade do conhecimento e da ressignificação das formas de intervenção do Estado nas políticas de escolarização que ocorrerá o desenvolvimento do Programme for International Student Assesment (PISA), pela Organização para Cooperação e Desenvolvimento Econômico (OCDE). A partir da aplicação de avaliações de larga escala, desde o ano 2000, o programa internacional produz sistemas de comparação de resultados, da mesma forma que induz programas de reforma dos sistemas de ensino (PONGRATZ, 2013). Em articulação às demandas de determinadas organizações internacionais, os objetivos dessas políticas, de acordo com Pongratz (2013), são “[...] a aplicação dos princípios de gestão do setor privado no setor público, a reestruturação da educação e das instituições de pesquisa de acordo com os princípios empresariais, a introdução de elementos de gestão de mercado em todos os níveis" (PONGRATZ, 2013, p. 143). Em síntese, o pesquisador alemão pontua que o PISA fabrica seus próprios padrões de normalidade.

A reestruturação das estratégias governamentais, nas tramas do neoliberalismo, desencadeia novas técnicas de governo. De acordo com Pongratz (2013), em uma perspectiva foucaultiana, há um deslocamento na "nova topografia neoliberal do social", favorecendo com que o exame ocupe um papel central. Sob tais condições, as reformas educativas são posicionadas como estratégias governamentais, promovendo novos valores e novos mecanismos de intervenção.

No âmbito do processo educativo, coloca-se em marcha um novo vocabulário, que entende o ensino como uma espécie de gestão da aprendizagem, como a disposição e o manejo de situações educativas que, em última instância, depende da própria pessoa a obtenção dos melhores resultados (ou falhar neste intento). (PONGRATZ, 2013, p. 148).

Conforme a analítica proposta por Pongratz (2013), a estratégia governamental predominante nas políticas focadas na escolarização é a "auto-organização" ou “organização da aprendizagem”. Nessas condições, o discurso da auto-organização constitui "[...] o coração da relação entre o poder e o conhecimento que une o neoliberalismo e a economização da educação com os sistemas e a teoria construtivista, com o fim de assimilar, mais a fundo que nunca, a educação na rede dos 
procedimentos disciplinares" (PONGRATZ, 2013, p. 147). O sujeito - aluno ou professor - torna-se seu próprio "centro de competência", na busca da gestão de qualidade. Os perfis formativos ou os padrões estatísticos advindos do PISA instalam-se nessas condições de escolarização.

Ampliando o escopo dessa argumentação, ainda precisamos assinalar duas questões relevantes. A primeira delas, junto ao sociólogo David Scott (2013), que o PISA apresenta-se como um dispositivo performativo, visto que "[...] sua intenção não é somente descrever as habilidades/disposições das crianças, mas sim promover e, portanto, contribuir para o desenho das políticas nacionais" (SCOTT, 2013, p. 75). Tais formas de conhecimento são fabricadas pela ação de determinados instrumentos que medem, nivelam e regulam a pauta formativa destinada à escolarização. Assim, há um forte investimento dos países para melhorar suas posições nos rankings, na medida em que tais resultados são reinscritos em seus contextos nacionais, por sistemas de comparação.

A outra questão diz respeito ao "privilégio dos números" na produção dos diagnósticos. Conforme os estudos de Popkewitz (2013, p. 92), esse privilégio apresenta-se como "[...] uma maneira de dizer a verdade sobre a vida social e as pessoas, pode ser expresso através de qualidades e características variadas e historicamente recentes na construção da vida moderna". Dessa argumentação deriva-se o entendimento de que, por meio dos sistemas comparativos fabricados internacionalmente, produz-se um campo de significação acerca dos saberes e das disciplinas escolares selecionadas, da mesma forma que novos conceitos pedagógicos são potencializados, permitindo a constituição de determinadas formas de exercer a docência. Nas palavras de Popkewitz (2013, p. 105, grifo do autor), “[...] as regras e normas da 'razão' do PISA constituem domínios de pessoas e torna-os estáveis a fim de calcular, deliberar e agir".

Ao problematizarmos as relações entre o contexto econômico e as políticas contemporâneas de escolarização, neste momento estabeleceremos uma aproximação aos escritos recentes de Stephen Ball (2010). Para essas relações, nos marcos desta abordagem teórica, faremos uso de dois conceitos advindos do aparato conceitual mobilizado pelo sociólogo britânico, a saber: performatividade e fabricações. Ao examinar os modos de constituição subjetiva dos professores, na contemporaneidade, Ball assinala a emergência de "[...] um novo modelo de regulação social (e moral), que atinge profundamente e imediatamente a prática dos professores do setor estatal reformando e re-formando sentidos e identidades, produzindo ou maquiando novas subjetividades profissionais" (BALL, 2010, p. 39, grifo do autor). O cenário descrito por Ball considera como ponto de partida o deslocamento das sociedades disciplinares para as sociedades de controle, conforme os indicativos de Deleuze. 
Tal deslocamento sugere que, do ponto de vista das tecnologias de poder, o foco não esteja centrado nas formas de vigilância sobre o trabalho do professor; mas a lógica é deslocada para dispositivos de controle contínuo. Uma das diferenças evidenciadas é que, sob a lógica do controle, os próprios indivíduos aspiram elevar seu desempenho. Em outras palavras, “[...] o que é produzido é um estado de permanente e consciente visibilidade (ou visibilidades) na intersecção do governo, da organização e da autoformação" (BALL, 2010, p. 40).

Para tratar dessa questão, o primeiro conceito mobilizado é o de "performatividade". Com a inspiração dos escritos de Lyotard, Ball (2010, p. 38) define o referido conceito como "[...] uma tecnologia, uma cultura e um modo de regulação". A performatividade materializa, analiticamente, duas noções fundamentais para a compreensão da sociedade contemporânea: a individualização das responsabilidades e a prestação de contas. Ao propor a intensificação das formas de desempenho, novas e permanentes estratégias de regulação do desempenho são colocadas em ação. No que se refere ao professor, sob tais condições esboçadas pela culpa, pela instabilidade e pela incerteza, emerge uma nova subjetividade. "Dentro desta economia da educação, interesses materiais e pessoais estão entrelaçados na competição por recursos, segurança e estima e na intensificação do trabalho profissional público - da transformação das condições e dos sentidos do trabalho" (BALL, 2010, p. 41).

Associado ao conceito de performatividade, Ball propõe o uso da noção de "fabricação". Em sua abordagem, inspiradas nos escritos políticos de Michel Foucault, as fabricações são versões específicas que os sujeitos constroem de si mesmos. Nas palavras do sociólogo, “[...] a fabricação se torna algo para ser mantido, vivido até; algo usado para avaliar práticas individuais. A disciplina do mercado é transformada em uma disciplina da imagem, do signo" (BALL, 2010, p. 45). Os próprios sujeitos, então, aspiram ingressar na lógica da performatividade, fabricando imagens positivas de si mesmos. Como nos lembra o autor, as instituições de ensino e seus profissionais dominam essa estratégia na atualidade.

No limite, a argumentação proposta pelo sociólogo permite-nos descrever a instauração de uma "sociedade performativa". Com a proliferação das formas empresariais, associadas à mercadorização do conhecimento, distanciam-se da profissão docente os atributos do profissionalismo tradicional. Os sujeitos aspiram tornar-se "empresários de si mesmos", em um quadro no qual “[...] são representados e encorajados a pensar sobre si mesmos como indivíduos que calculam a si mesmos, que agregam valor a si mesmos, que melhoram sua produtividade, que vivem uma existência de cálculo" (BALL, 2010, p. 51).

$\mathrm{Na}$ presente seção, procuramos revisitar a literatura contemporânea, em uma perspectiva internacional, acerca das novas formas de regulação advindas 
do cenário neoliberal. Tomando a constituição dos processos de avaliação de larga escala como fio condutor de nossa argumentação, especialmente o PISA, procuramos cartografar o campo das políticas de escolarização na contemporaneidade. A perspectiva dos autores escolhidos para esta revisão converge no sentido do delineamento de uma nova concepção de docência, fabricada nas tramas do capitalismo contemporâneo. Seja pelo reconhecimento do professor como seu "próprio centro de competência" (PONGRATZ, 2013), ou ainda pela emergência de "novas formas de governança" (LUNDGREN, 2013), importa reconhecer que, na perspectiva analítica proposta por Ball (2010), estamos ingressando em uma "sociedade performativa".

De quais modos esse cenário produz ressonâncias nas políticas de formação de professores atualmente engendradas em nosso país? Quais sentidos políticos e pedagógicos orientam os professores alfabetizadores em suas novas formas de formação continuada? Na próxima seção, perscrutaremos tais questionamentos a partir da aproximação empírica às condições de emergência e aos principais delineamentos do Pacto Nacional pela Alfabetização na Idade Certa.

\section{Cartografando o PNAIC: condições de emergência e caracterização do programa}

Os discursos sobre a necessidade de mudança no campo da educação tomam a formação continuada de professores como expressão privilegiada, tendo em vista seus programas financiados e desenvolvidos pelo governo. Conforme Hypólito (2010), tais discursos objetivam a disseminação da noção de que as reformas educacionais são uma necessidade natural para que o país se desenvolva e avance economicamente. Desse modo, de acordo com o referido autor, as reformas educacionais são posicionadas como parte inevitável da globalização, do mercado internacional e de uma economia que, por ser considerada cada vez mais focalizada no conhecimento, exige mudanças radicais na forma de organizar, conceber e desenvolver a educação no país. Para tanto, como começamos a destacar na seção anterior, a racionalidade que marca as políticas reformistas informa sobre a necessidade de investir-se em estratégias discursivas que convençam, seduzam e gerenciem os sujeitos, conformando todos aos diferentes papeis necessários para a missão de recuperar a qualidade da educação (POPKEWITZ, 2004; BALL, 2004).

Por meio de práticas avaliativas, a falta de qualidade da educação é apresentada como um problema social cuja solução encontra-se na produção de uma regulação mais intensa, que, consequentemente, só pode ser operacionalizada a partir de novos processos avaliativos. Desse modo, a divulgação dos resultados das avaliações passa a operar de forma produtiva, identificando e constituindo um sistema, uma escola e um professor ou alfabetizador qualificados para ação 
em uma sociedade do conhecimento (LESSARD, 2006). A situação brasileira, no contexto desta "sociedade performativa" (BALL, 2010), parece acompanhar semelhantes tendências.

Em tal lógica, na gestão do então presidente Luiz Inácio Lula da Silva², foi apresentado como plano de governo para o campo da educação o documento intitulado Uma escola do tamanho do Brasil (PARTIDO DOS TRABALHADORES, 2002). No documento, a educação foi apontada como uma prioridade, sendo considerada como um aspecto estratégico para a transformação econômica e social brasileira. Além disso, foi destacada a necessidade de mapeamento do rendimento dos alunos por meio de avaliações em larga escala e a importância de serem criados programas de formação continuada de professores. Em 2003, após o diagnóstico do Ministério da Educação (MEC) acerca da necessidade de melhorar os resultados obtidos no Sistema de Avaliação Nacional da Educação Básica $(\mathrm{SAEB})^{3}$, passaram a ser implementados programas de formação para os professores da Educação Básica que visavam a melhoria dos resultados que estavam sendo obtidos nas avaliações nacionais. Os argumentos apresentados apontavam a urgência de serem revertidos os índices de fracasso escolar na Educação Básica e sinalizavam a necessidade de que se procedesse a um intenso acompanhamento das práticas docentes junto aos alunos.

Nessa direção, visando reverter os índices de desempenho dos alunos a partir do investimento em educação e da qualificação dos profissionais da Educação Básica por meio da formação continuada, foi desenvolvida uma série de medidas, dentre as quais destaca-se a criação da Rede Nacional de Formação Continuada de Professores de Educação Básica (2004) ${ }^{4}$, do Programa Pró-Letramento (2005), do Plano de Desenvolvimento da Educação - PDE (2007), do Plano de Metas Compromisso Todos pela Educação ${ }^{5}$, do Índice de Desenvolvimento da Educação Básica (IDEB), do Fundo de Manutenção e Desenvolvimento da Educação Básica e da valorização dos Profissionais da Educação (FUNDEB) ${ }^{6}$. A

${ }^{2}$ O plano de governo para educação Uma escola do tamanho do Brasil foi desenvolvido a partir da primeira gestão do presidente (2002-2005), tendo continuidade na sua segunda gestão (2006-2009).

${ }^{3}$ De acordo com o MEC, no documento Fracasso Escolar no Brasil: políticas, programas e estratégias de prevenção ao fracasso escolar (BRASIL, 2005), no que se refere ao desempenho dos alunos da então $4^{\text {a }}$ série do Ensino Fundamental no SAEB/2003, o resultado foi de 36,7\% de alunos com nível de desempenho crítico em Língua Portuguesa e de 40,1\% de alunos com nível de desempenho crítico em Matemática.

${ }^{4}$ A Rede Nacional de Formação Continuada de Professores de Educação Básica (2004) foi criada com o objetivo de contribuir para a melhoria da formação dos professores e de modo correlato com a reversão dos baixos índices de desempenho apresentados pelos alunos no SAEB/2003.

${ }^{5}$ O Plano de metas Compromisso Todos pela Educação foi promulgado pelo decreto lei 6.094/2007 (BRASIL, 2007a), assim como o Índice de Desenvolvimento da Educação Básica (IDEB).

${ }^{6}$ O FUNDEB foi criado pela Emenda Constitucional no 53/2006 (BRASIL, 2006) e regulamentado pela lei $\mathrm{n}^{\circ} 11.494 / 2007$ (BRASIL, 2007b) e pelo decreto $\mathrm{n}^{\circ}$ 6.253/2007 (BRASIL, 2007c). 
partir de tais medidas, passa a operar o que Ball (2004) denomina como sendo o "novo panopticismo da gestão", uma vez que novas formas de controle passam a incidir diretamente em mudanças no ato de ensinar e, de modo correlato, na subjetividade docente.

Em relação às medidas elencadas, interessa-nos especialmente o Programa de Formação de Professores Pró-Letramento, pelo fato de ele ter sido tomado como referência para elaboração do PNAIC e considerado exitoso pelo MEC, mediante a análise de seus resultados. Os resultados do IDEB e da Prova Brasil alcançados nos anos iniciais do Ensino Fundamental, em 2007 e 2009, superaram as metas estimadas na época. Como apontam Popkewitz e Lindblad (2001), no campo educacional contemporâneo, as estatísticas escolares avaliativas têm promovido a intensa descrição de definição do que são problemas educacionais, assim como a elaboração de uma extensa agenda de programas de reforma.

Na perspectiva de enfrentamento dos problemas educacionais, o Pró-Letramento foi um programa de formação continuada destinado a professores em exercício nos anos iniciais do Ensino Fundamental das escolas públicas. $\mathrm{O}$ programa, com duração de dois anos, foi lançado em 2005 como ação integrante do Plano Nacional de Qualidade da Educação Básica, sendo reeditado em 2007, como parte das ações de formação de professores do Plano de Desenvolvimento da Educação (PDE). O objetivo central do programa foi o de oferecer suporte à ação pedagógica dos professores tendo em vista o interesse em elevar a qualidade do ensino e da aprendizagem nos componentes curriculares de Língua Portuguesa e de Matemática. Para tanto, o programa buscou desenvolver uma cultura de formação continuada em rede, envolvendo Universidades, Secretarias de Educação e Escolas Públicas dos Sistemas de Ensino.

Prosseguindo com as propostas para o campo da educação e com a agenda reformista, no governo Dilma Rousseff (2010-2014) foram retomados programas implementados durante o governo Luis Inácio Lula da Silva (2003-2010) e criados outros, como o Programa Nacional de Acesso ao Ensino Técnico e Emprego - PRONATEC (2011) e o Pacto Nacional pela Alfabetização na Idade Certa PNAIC (2012). O PNAIC foi instituído pela portaria $\mathrm{n}^{\circ} 867$, de 4 de julho de 2012, que definiu ações e diretrizes para o Programa. Inicialmente, o programa com duração de dois anos ${ }^{7}$ é destinado à formação continuada de professores alfabetizadores, que atuam nas turmas de $1^{\circ}, 2^{\circ}$ e $3^{\circ}$ anos do Ensino Fundamental. Essa formação consiste em encontros de estudo e atividades práticas coordenadas pelos orientadores, também professores da rede pública de ensino. Desse modo, o PNAIC tem como objetivos:

${ }^{7}$ No desenvolvimento de sua implementação, o prazo foi ampliado em mais um ano de atividades. 
I - garantir que todos os estudantes dos sistemas públicos de ensino estejam alfabetizados, em Língua Portuguesa e em Matemática;

II - reduzir a distorção idade/série na Educação Básica;

III - melhorar o Índice de Desenvolvimento da Educação Básica (IDEB);

IV - contribuir para o aperfeiçoamento da formação dos V - construir propostas para a definição dos direitos de aprendizagem e desenvolvimento das crianças nos três primeiros anos do ensino fundamental. professores alfabetizadores;

$\mathrm{V}$ - construir propostas para a definição dos direitos de aprendizagem e desenvolvimento das crianças nos três primeiros anos do ensino fundamental. (BRASIL, 2012a, p. 2).

Nesse sentido, são assumidos os seguintes compromissos pelo PNAIC: a) A promoção da alfabetização em Língua Portuguesa e Matemática; b) A realização de avaliações anuais por meio do Instituto Nacional de Estudos e Pesquisas Educacionais Anísio Teixeira (INEP), para os alunos concluintes do $3^{\circ}$ ano do Ensino Fundamental; c) O apoio gerencial dos estados aos municípios que tenham aderido ao PNAIC para a sua efetiva implementação. Diante dos compromissos assumidos pelo programa, são previstas ações que contemplam os seguintes eixos: a) Formação continuada de professores alfabetizadores; b) Materiais didáticos e pedagógicos; c) Gestão, controle social e mobilização.

O primeiro eixo de desenvolvimento do PNAIC é a formação continuada de professores alfabetizadores. Inicialmente, é realizada a formação de um conjunto de professores orientadores de estudos, para o posterior desenvolvimento da formação dos professores alfabetizadores. A formação continuada constitui-se em um curso presencial com duração de dois anos para os professores alfabetizadores, com carga horária de 120 horas por ano ${ }^{8}$. Esses encontros são coordenados pelos orientadores de estudos, que recebem a formação teórica e metodológica em instituições de Ensino Superior. Os professores alfabetizadores e orientadores de estudos participantes do PNAIC recebem bolsa de estudos financiada pelo Fundo Nacional de Desenvolvimento da Educação (FNDE). O segundo eixo do programa são os materiais didáticos e pedagógicos. Para os professores alfabetizadores do primeiro ciclo participantes do PNAIC são disponibilizados materiais didáticos para alfabetização, tais como: livros didáticos, dicionários, jogos pedagógicos, obras literárias e obras pedagógicas complementares, além de suporte da TV Escola, Portal do Professor e Banco Internacional de Objetos.

A avaliação é definida como o terceiro eixo do PNAIC. O processo avaliativo contempla a realização da análise do nível de alfabetização dos alunos a partir da qual pretende-se acompanhar a eficácia, os resultados do Pacto e implementar

\footnotetext{
${ }^{8}$ A partir de seu segundo ano, a carga horária anual foi ampliada para 160 horas-aula, de maneira que desse conta das áreas de Língua Portuguesa e Matemática.
} 
soluções corretivas para as deficiências didáticas encontradas em cada localidade. A avaliação por meio da Provinha Brasil é realizada anualmente, pelas próprias redes de ensino, dirigida aos estudantes das escolas participantes, no início e no final do segundo ano do Ensino Fundamental. Além disso, é prevista a realização pelo INEP de uma avaliação externa universal do nível de alfabetização dos alunos ao final do terceiro ano do Ensino Fundamental'. Tais práticas avaliativas, ao identificarem os déficits e qualificarem a educação, configuram-se como práticas que produzem os modos de ser e de agir dos docentes, dos discentes e dos gestores, bem como da maneira como a sociedade entende a ação desses sujeitos (ANADON, 2012; VEIGA-NETO, 2013). Por fim, a gestão, o controle social e a mobilização são definidos como o quarto eixo do Pacto. Trata-se de um sistema de gestão e de monitoramento que tem o intuito de assegurar a implementação do PNAIC. O sistema de monitoramento (SisPacto), disponibilizado no Sistema Integrado de Monitoramento Execução e Controle (SIMEC), possibilita o acompanhamento constante pelas pessoas envolvidas no PNAIC.

A partir da exposição sobre as condições de emergência do PNAIC, bem como da caracterização do programa, é possível perceber a presença do que Veiga-Neto (2013) tem definido como um "desvio à direita", ou seja, uma reorganização na sequência tradicional das operações curriculares. Conforme o autor, a sequência tradicional constituída pelo planejamento - execução - avaliação passou a ser avaliação - planejamento - execução. Isso porque a avaliação tornou-se o foco das reformas curriculares, com uma exaltação excessiva do seu poder de solucionar os problemas educacionais. Fato claramente evidenciado no PNAIC, assim como no Pró-Letramento enquanto programa antecessor.

Considerando a retomada da história recente das políticas de formação de professores alfabetizadores no Brasil, parece-nos conveniente estendermos nosso olhar aos documentos orientadores do PNAIC. Na próxima seção, almejamos analisar os fundamentos dessa política, em cruzamento com o diagnóstico sociológico que empreendemos na primeira seção deste artigo.

\section{O PNAIC em perspectiva: entre o desempenho e a inovação permanente}

O Pacto Nacional pela Alfabetização na Idade Certa, mais recente iniciativa do governo brasileiro destinada à formação de professores alfabetizadores, apresenta uma estrutura organizativa peculiar. Assenta-se na possibilidade de mobilizar os diferentes entes federativos, bem como a sociedade civil, na direção de um mesmo objetivo. De acordo com seu documento orientador,

\footnotetext{
${ }^{9}$ A avaliação referida trata-se da Avaliação Nacional de Alfabetização, coordenada pelo INEP. É dirigida aos estudantes matriculados no terceiro ano do Ensino Fundamental.
} 
[...] as ações do Pacto são um conjunto integrado de programas, materiais e referências curriculares e pedagógicas que serão disponibilizados pelo Ministério da Educação e que contribuem para a alfabetização e o letramento, tendo como eixo principal a formação continuada dos professores alfabetizadores. (BRASIL, 2012a, p. 11).

Considerando, inicialmente, esse compromisso de mobilização nacional em torno da questão, constatamos, de forma preliminar, um deslocamento nas estratégias de intervenção do Estado, na direção de "novas formas de governança" (BALL, 2013; LUNDGREN, 2013).

De acordo com Ball, podemos constatar uma reconfiguração das formas de governo das políticas, situada em um cenário de rearticulação das formas públicas e privadas e de ampliação da esfera de atuação do Estado (BALL, 2013). Sob tais condições, emergem um conjunto de novos especialistas, institutos de pesquisa e de inovação e setores voluntários destinados a ampliar o espaço de atuação do Estado. "Portanto, novas vozes e interesses são representados no processo político, e novos nós de poder e influência são construídos e fortalecidos" (BALL, 2013, p. 177). A produção de um "pacto" que mobiliza diferentes entes federativos e a sociedade civil na direção de um objetivo pode ser situada, em nossa leitura, no âmbito de determinadas "formas de governança". Especificamente acerca das políticas de formação de professores alfabetizadores, essa questão adquire nuances específicas.

Acompanhando a história das políticas de alfabetização, em um cenário internacional, Viñao Frago (1993) esclarece que, ao longo do século XX, ocorreu uma mutação nas formas de entendimento sobre a questão. De uma perspectiva inicial que atribuía centralidade ao analfabetismo, percebido como uma carência ou uma patologia a ser erradicada, “[...] o centro de atenção deslocou-se do analfabetismo para o processo de alfabetização, seus agentes e modos de atuação" (VIÑA FRAGO, 1993, p. 31). Essa virada interpretativa permitiu perceber a emergência dos entendimentos da alfabetização como uma prática cultural, conduzida por aspectos mais amplos. Em síntese, na leitura proposta pelo pesquisador espanhol, notava-se “[...] a relevância, no processo de alfabetização, de aspectos ideológico-cultural-proselitistas, frente aos que acentuavam o peso de fatores estruturais sócio-econômicos e geográficos" (VIÑAO FRAGO, 1993, p. 32).

O deslocamento descrito por Viñao Frago - do analfabetismo como uma patologia para a alfabetização como um processo cultural - denotava como chave de leitura a "funcionalidade externa" dessa questão, vinculando-a aos regimes de implementação das políticas de escolarização.

A funcionalidade externa supõe que o impulso ou pressão para a alfabetização e/ou escolarização origina-se no exterior dos indivíduos ou grupos envolvidos. 
Costuma ser conseqüência de uma pressão ideológico-proselitista ou de uma ação de controle social efetuada habitualmente com o apoio eclesiástico e/ou público (estatal ou local), e traduz-se em disposições, informes, campanhas, programas de ação, etc., e toda uma literatura de apoio sobre as excelências da alfabetização e da escola. Em suma, ambas são geradas e trazidas a partir de fora e impostas ou propiciadas e aceitas por seus usuários. (VIÑAO FRAGO, 1993, p. 39).

Apoiados na hipótese histórica das funcionalidades externas da alfabetização, desenvolvida por Viñao Frago (1993), notamos que, hodiernamente, um novo deslocamento faz-se visível nos regimes de implementação das políticas de escolarização ligadas à alfabetização. De uma lógica da erradicação e de uma perspectiva culturalista, emergem atualmente programas de formação de professores alfabetizadores que apresentam como sentido de suas ações a ampliação do campo de influência das estatísticas educacionais, visando a intensificação dos padrões de competitividade dos sujeitos e das nações. Sob os auspícios de novos regimes de governança (BALL, 2004, 2010), materializados na centralidade das avaliações de larga escala e dos padrões internacionalmente engendrados (LUNDGREN, 2013), argumentaremos que as políticas de formação de alfabetizadores no Brasil são regidas por duas estratégias distintas e complementares, a saber: a ênfase na regulação dos desempenhos e a busca de perfis formativos inovadores.

\section{- A ênfase na regulação dos desempenhos}

No contexto das políticas educacionais, as avaliações em larga escala têm se configurado como um instrumento regulatório de uma Estado-avaliador, cujos resultados objetivam estabelecer rankings entre as redes de ensino, deflagrando a competição e pressionando os professores por melhores desempenhos (ANADON, 2012). O investimento na performatividade por meio da preparação dos estudantes para realização de avaliações possibilita o monitoramento do Estado e facilita sua interferência nas culturas, nas práticas e nas subjetividades das instituições educativas e de seus profissionais (MOREIRA, 2009; HYPÓLITO, 2010).

No contexto brasileiro contemporâneo, é possível reconhecer a presença marcante de tal performatividade, quando se observam as pressões exercidas sobre os professores das escolas, por meio da realização sistemática de avaliações de larga escala, nas quais predomina uma racionalidade mercantil que valoriza os indicadores estatísticos, desconsiderando as especificidades dos contextos educativos. O próprio documento do PNAIC sobre a avaliação no ciclo de alfabetização reitera em seu discurso a importância da aferição do nível de desempenho dos estudantes mediante a realização de avaliações em larga escala, salientando que os resultados de tais avaliações podem "[...] contribuir para que se possa articular 
o que o professor se propõe a ensinar e o que avalia com base nos instrumentos oficiais" (BRASIL, 2012b, p.10).

Por esse motivo, no âmbito do PNAIC, a formação e a atuação de professores alfabetizadores são consideradas como medidas estratégicas para o alcance da meta de alfabetização dos estudantes matriculados nas escolas públicas brasileiras até o final do terceiro ano do Ensino Fundamental. Para tanto, os sistemas públicos de ensino ao aderirem ao PNAIC passam a ser continuamente monitorados por meio de avaliações sistemáticas, cuja ênfase encontra-se focalizada na regulação do desempenho dos estudantes e de modo correlato na responsabilização dos professores pelos resultados obtidos nas avaliações nacionais. As verdades produzidas no que diz respeito à defesa de avaliações padronizadas vêm sendo construídas no contexto brasileiro a partir de pesquisas e de estatísticas que têm estabelecido rankings de desempenho para o sistema escolar, conforme evidenciado na seção anterior.

A partir das avaliações, institui-se uma vigilância sobre o ser e o fazer docente (POPKEWITZ, 2004; LESSARD, 2006). O PNAIC, ao operar no nível das sensibilidades, disposições e consciências dos professores alfabetizadores, inscreve racionalidades políticas que permitem governar a escola a partir da promoção de mudanças nas capacidades interiores dos sujeitos docentes (POPKEWITZ, 2004). Desse modo, a geração de dados sobre o nível de alfabetização dos estudantes, por meio das avaliações, é entendida como uma medida estratégica para conhecerem-se (e produzirem-se) informações sobre os estudantes e, assim, poder intervir por intermédio da implantação do que o governo federal denomina como políticas corretivas. Isso porque os dados produzidos pelas avaliações em larga escala produzem e reiteram a necessidade de existência do PNAIC, já que os números governam “[...] não como 'puros' números, mas por meio do entrecruzamento de discursos paralelos que circulam pelos relatórios para traçar perfis e inventariar pessoas" (POPKEWITZ; LINDBLAD, 2001, p. 126).

A ênfase do PNAIC na importância de serem realizadas avaliações com o objetivo de aferir resultados, produzir estatísticas e estabelecer rankings, com o intuito de regular desempenhos, é a tônica das orientações apresentadas nos manuais de implantação. É por meio dos resultados de avaliações que são fabricadas verdades a respeito do nível de alfabetização dos estudantes e sobre o modo como devem atuar os docentes. Corroborando o argumento apresentado, consideramos oportuno apresentar os componentes das avaliações propostas pelo PNAIC, como pode ser observado no excerto a seguir.

Avaliações: Este eixo reúne três componentes principais: avaliações processuais, debatidas durante o curso de formação, que podem ser desenvolvidas e realizadas continuamente pelo professor junto aos educandos. A segunda 
mudança refere-se à disponibilização de um sistema informatizado no qual os professores deverão inserir os resultados da Provinha Brasil de cada criança, no início e no final do $2^{\circ}$ ano e que permitirá aos docentes gestores analisar de forma agregada essas informações e adotar eventuais ajustes. A terceira medida é a aplicação, junto aos alunos concluintes do $3^{\circ}$ ano, de uma avaliação externa universal, pelo INEP, visando aferir o nível de alfabetização alcançado ao final do ciclo, e que possibilitará às redes implementar medidas e políticas corretivas. (BRASIL, 2012a, p. 13).

Conforme pode ser observado, são apresentadas três modalidades avaliativas. A primeira modalidade é a avaliação processual, realizada pelos alfabetizadores nas escolas; já a segunda é a Provinha Brasil, realizada no início e no final do segundo ano do Ensino Fundamental; e a terceira consiste em uma avaliação final, que será realizada pelo INEP, no intuito de aferir o nível de alfabetização no final do terceiro ano. Embora a primeira modalidade avaliativa seja realizada pelos professores em sala de aula, o princípio orientador é a aferição de desempenhos mediante avaliações de larga escala. Tais práticas avaliativas encontram-se localizadas dentro de um contexto reformista, a partir do qual percebemos a difusão de discursos sobre a importância de que sejam desenvolvidas práticas de ensino eficazes que possibilitem o alcance de bons resultados nas avaliações.

Delineia-se, desse modo, conforme Santos (2004, p. 1146), “[...] uma nova arquitetura para o setor educacional edificada a partir de critérios de eficiência e eficácia em consonância com os interesses do mercado”. Arquitetura que tem redefinido as formas de trabalho e instituído outras relações dos professores alfabetizadores com suas atividades cotidianas em sala de aula, produzindo o que Popkewitz e Lindblad (2001) vêm denominando como "individualidades docentes autogovernadas". A preocupação dos professores passa a ser, então, com a preparação dos estudantes para as avaliações, tendo em vista uma boa colocação da escola em que atuam nos rankings municipal, regional ou nacional. Nesse sistema, que tem a performatividade como base, o que interessa são os resultados. Isso porque as equipes gestoras das redes de ensino, bem como os professores que fazem parte delas, sabem que, conforme consta no manual do PNAIC, será publicado pelo Ministério da Educação um edital " [...] informando os critérios de premiação e reconhecimento aos professores, escolas e redes de ensino que mais avançarem na alfabetização de suas crianças, considerando os resultados aferidos nas avaliações” (BRASIL, 2012a, p. 13). Desse modo, nos processos de alfabetização, cria-se uma busca incessante por melhores resultados nas avaliações.

\section{- A busca de perfis formativos inovadores}

A busca de perfis formativos inovadores, no que tange às políticas de escolarização contemporâneas, emerge de maneira enfática na composição dos 
discursos pedagógicos. Ao examinar as mudanças culturais que interpelam a escola de nosso tempo, Sibilia (2012) pontua a aproximação das questões da educação e da cultura com a lógica do capital, delineada pelo consumo em suas diferentes nuances. Na medida em que a educação não é mais apresentada nas condições modernas, de escolarização obrigatória, passa a ser "oferecida como fast food ou em sua versão gourmet" (SIBILIA, 2012, p. 132, grifo do autor). As práticas pedagógicas mobilizadas são impulsionadas a tornarem-se úteis, divertidas e estimulantes, fazendo com que o aluno aproxime-se da figura de um cliente - "[...] aquele que sempre tem razão e que deseja se divertir, ou, de algum modo, lucrar com seus investimentos" (SIBILIA, 2012, p. 132).

A preocupação com o discurso da inovação pedagógica também é sinalizada no diagnóstico das políticas educacionais produzido por Pongratz (2013), já problematizado na primeira seção. De acordo com o pesquisador, cada estudante e cada professor tornam-se "seu próprio centro de competência", o que implica em uma reflexão sobre um novo vocabulário emergente. Em suas palavras, "[...] coloca-se em marcha um novo vocabulário que entende o ensino como uma espécie de gestão da aprendizagem, como a disposição e o manejo de situações educativas, o que depende das próprias pessoas, em última instância, a obtenção dos melhores resultados" (PONGRATZ, 2013, p. 148). Ainda, conforme o autor, nota-se um deslocamento nas formas de condução do trabalho pedagógico que, junto à subjetividade docente, fazem do professor um gestor de projetos, designado por determinadas estratégias políticas que fabricam uma "vontade de qualidade".

Ao observarmos os regimes de implementação do PNAIC, constatamos que há uma intensa preocupação de uma docência capaz de atender aos desafios da alfabetização no século XXI. Tal lógica, associa-se a uma busca por práticas inovadoras e diferenciadas aos perfis dos diferentes públicos, regidas pela melhoria do desempenho. O excerto a seguir descreve um primeiro campo de visibilidades para essa questão.

Os sistemas de ensino devem se organizar para lançar mão de estratégias de acompanhamento especial às crianças que, em relação aos objetivos esperados, estejam precisando de apoio pedagógico mais intenso e diferenciado. $\mathrm{O}$ Programa Mais Educação, por exemplo, poderá ser estruturado para ampliação da jornada com foco no Ciclo de Alfabetização. (BRASIL, 2012a, p. 35).

Nessa direção, o manual orientador das atividades do PNAIC descreve a relevância da formação permanente, de modo que construa capacidades de intervenção para alfabetizar em um mundo em mudança. De acordo com o documento, "[...] existem vários métodos e estratégias de alfabetização. Todavia, é importante destacar que as novas demandas colocadas pelas práticas sociais de leitura e de escrita têm criado novas formas de pensar e conceber o fenômeno da alfabetiza- 
ção" (BRASIL, 2012b, p. 19). A referida preocupação vincula-se ao diagnóstico oferecido por Lundgren (2013, p. 26, grifo do autor), acerca das condições de uma sociedade do conhecimento, quando "[...] este conceito de 'alfabetização' (literacy) começou a aparecer em paralelo com o de competência". Especificamente, em um cenário de intensas transformações sociais e econômicas, os debates acerca das competências adquirem nova centralidade nas políticas de escolarização.

Os instrumentos utilizados para mobilizar o PNAIC, considerados como fatores determinantes para o êxito no processo de alfabetização, como sinalizamos na seção anterior, remetem-se à ação dos docentes, ao uso de materiais didáticos estimulantes e ao monitoramento das atividades desenvolvidas. $O$ primeiro fator diz respeito aos padrões subjetivos esperados pelos docentes, a saber: "[...] em primeiro lugar, é fundamental contar com professores alfabetizadores bem preparados, motivados e comprometidos com o desafio de orientar as crianças nesta etapa da trajetória escolar" (BRASIL, 2012a, p. 20). O segundo fator, ligado ao uso de materiais pertinentes, indica que “[...] não basta dispor desses materiais, é fundamental que os professores saibam manuseá-los e extrair dos conteúdos o máximo de possibilidades para dinamizar as aulas e alcançar os objetivos da alfabetização em cada ano" (BRASIL, 2012a, p. 20). Apresenta-se de forma indispensável a composição de novas significações em torno da ação docente. Todavia, será o terceiro fator que demarcará a estreita aproximação entre as práticas docentes inovadoras e a ênfase na regulação dos desempenhos, explicitada anteriormente.

Por fim, mas não por último, destaca-se que o êxito do processo de alfabetização reside também na capacidade de acompanhar continuamente o progresso da aprendizagem das crianças, por meio de avaliações contínuas, que podem ser baseadas em observações e registros sistemáticos de cada criança, bem como por avaliações estruturadas, a exemplo da Provinha Brasil. (BRASIL, 2012a, p. 21).

A inovação nos processos de alfabetização seria garantida, de acordo com o Manual do PNAIC, por meio de docentes motivados e preparados para atuar em um mundo em mudança, que mobilizem recursos estimulantes e que, permanentemente, avaliem o desenvolvimento de seu trabalho. Retomando a abordagem de Pongratz (2013), postulando a reforma educativa como uma estratégia governamental, vinculada a "sistemas de auto-organização", nos quais, nas condições do neoliberalismo, "[...] o Estado não se retira por completo dos eventos, mas sim converte-se em um 'vigilante' e deixa a atuação para os atores (da educação)" (PONGRATZ, 2013, p. 150, grifo do autor). Importa ainda reiterar que, em tais condições, essa " $[. .$.$] forma avançada de governamentalidade neoliberal no sis-$ tema educativo surge da união do aparato escolar com a demanda incessante da autogestão" (PONGRATZ, 2013, p. 149). 


\section{Considerações finais}

Por toda parte, parece que, por si só e num passe de mágica, do aperfeiçoamento da avaliação resultará o aperfeiçoamento da educação para que, num outro passe de mágica se atinja o soi-disant 'progresso social'. O salvacionismo pedagógico continua vivo e forte. Nesse jogo, o que parece ter mudado é onde estão sendo colocadas as fichas da esperança; nem tanto no planejamento e nem tanto na execução, mas sobretudo na avaliação

(VEIGA-NETO, 2013, p. 166).

$\mathrm{Na}$ analítica ora exposta, tomamos as estratégias políticas do Pacto Nacional pela Alfabetização na Idade Certa (PNAIC) como objeto reflexivo, considerando-as como expressivas de um conjunto de reformas educacionais mobilizadas pelo Estado Brasileiro nas últimas décadas. A formação de professores alfabetizadores configura importante dimensão das políticas contemporâneas de escolarização e, como procuramos demonstrar, evidencia um conjunto de indícios sobre os modos de efetivação, de regulação, de gestão e de avaliação de tais políticas.

Ao revisarmos o contexto internacional das reformas educacionais (PONGRATZ, 2013; LUNDGREN, 2013; BALL, 2004, 2010; POPKEWITZ, 2013), reconhecemos que as concepções de formação de professores colocadas em ação são potencializadas pelos modos de individualização dos percursos formativos, ao mesmo tempo em que intensificam as formas de gestão governamental da ação dos professores alfabetizadores. O PNAIC, no Brasil, é sintomático de um conjunto de tensionamentos endógenos e, principalmente, exógenos aos contextos de formulação das políticas, sendo, pois, condicionado por diversas referências discursivas que, para além de seus contornos ideológicos, interferem no regime de suas práticas e nas situações cotidianas experimentadas por seus atores. Avaliação de larga escala, inovação permanente, potencialização de desempenhos, gestão pedagógicas das inovações e perfis formativos inovadores operam como referências às políticas e às práticas de formação de professores alfabetizadores evidenciadas no PNAIC.

Por fim, concluímos que tal intervenção formativa, ao apostar nos modelos de avaliação de larga escala como objetivo estratégico, produz esforços na direção de uma docência em inovação permanente, apropriada para os regimes de inspiração neoliberal, predominantes nas políticas de escolarização mobilizadas em nosso país. Como assinalamos ao longo deste texto, o professor alfabetizador é interpelado a assumir responsabilidades específicas na formação dos estudantes, ao mesmo tempo em que é seduzido a investir em sua própria formação, de modo que qualifique seu desempenho, qualifique os resultados de sua escola e estimule suas capacidades inovadoras em uma nova arquitetura institucional. 


\section{Referências}

ANADON, S. B. Prova Brasil: uma estratégia de governamentalidade. 2012. 170 f. Tese (Doutorado em Educação) - Faculdade de Educação da Universidade Federal de Pelotas, Pelotas, 2012.

BALL, S. J. Performatividade, privatização e o pós-estado do bem-estar. Educação \& Sociedade, Campinas, v. 25, n. 89, p. 1105-1126, set./dez. 2004. DOI: 10.1590/S0101-73302004000400002

BALL, S. J. Performatividades e fabricações na Economia Educacional: rumo a uma sociedade performativa. Educação \& Realidade, Porto Alegre, v. 35, n. 2, p. 37-55, maio/ago. 2010.

BALL, S. J. Novos Estados, nova governança e nova política educacional. In: APPLE, M.; BALL, S.; GANDIN, L. A. (Orgs.). Sociologia da educação: análise internacional. Porto Alegre: Penso, 2013. p. 177-189.

BRASIL. Secretaria de Educação Infantil e Ensino Fundamental. Departamento de Políticas Educacionais. Fracasso escolar no Brasil: Políticas, programas e estratégias de prevenção ao fracasso escolar. Brasília: Ministério da Educação, 2005.

BRASIL. Emenda Constitucional no 53, de 19 de dezembro de 2006. Dá nova redação aos arts. $7^{\circ}, 23,30,206,208,211$ e 212 da Constituição Federal e ao art. 60 do Ato das Disposições Constitucionais Transitórias. Diário Oficial da União, Brasília, 20 dez. 2006.

BRASIL. Decreto no 6.094, de 24 de abril de 2007. Dispõe sobre a implementação do Plano de Metas Compromisso Todos pela Educação, pela União Federal, em regime de colaboração com Municípios, Distrito Federal e Estados, e a participação das famílias e da comunidade, mediante programas e ações de assistência técnica e financeira, visando a mobilização social pela melhoria da qualidade da educação básica. Diário Oficial da União, Brasília, 25 abr. 2007a.

BRASIL. Lei no 11.494, de 20 de junho de 2007. Regulamenta o Fundo de Manutenção e Desenvolvimento da Educação Básica e de Valorização dos Profissionais da Educação FUNDEB, de que trata o art. 60 do Ato das Disposições Constitucionais Transitórias; altera a Lei no 10.195, de 14 de fevereiro de 2001; revoga dispositivos das Leis nos 9.424, de 24 de dezembro de 1996, 10.880, de 9 de junho de 2004, e 10.845, de 5 de março de 2004; e dá outras providências. Diário Oficial da União, Brasília, 21 jun. $2007 \mathrm{~b}$.

BRASIL. Decreto $n^{\circ}$ 6.253, de 13 de novembro de 2007. Dispõe sobre o Fundo de Manutenção e Desenvolvimento da Educação Básica e de Valorização dos Profissionais da Educação FUNDEB, regulamenta a Lei no 11.494 , de 20 de junho de 2007, e dá outras providências. Diário Oficial da União, Brasília, 14 nov. 2007c.

BRASIL. Manual do pacto. Pacto Nacional pela Alfabetização na Idade Certa: o Brasil do futuro com o começo que ele merece. Brasília: Ministério da Educação, 2012a.

BRASIL. Pacto Nacional pela Alfabetização na Idade Certa. Avaliação no ciclo de alfabetização: reflexões e sugestões. Brasília: Ministério da Educação, 2012b.

HYPOLITO, A. M. Políticas curriculares, Estado e regulação. Educação \& Sociedade, Campinas, v. 31, n. 113, p. 1337-1354, out./dez. 2010. DOI: 10.1590/S0101-73302010000400015

LESSARD, C. A universidade e a formação profissional dos docentes: novos questionamentos. Educação \& Sociedade, Campinas, v. 27, n. 94, p. 201-227, jan./abr. 2006. DOI: 10.1590/ S0101-73302006000100010 
LUNDGREN, U. Pisa como instrumento político: la historia detrás de la creación del programa Pisa. Profesorado - revista de currículum y formación del profesorado, Granada, v. 17, n. 2, p. 15-29, maio/ago. 2013.

MOREIRA, A. F. A cultura da performatividade e a avaliação da pós-graduação em educação no Brasil. Educação em Revista, Belo Horizonte, v. 35, n. 3, p. 23-42, dez. 2009. DOI: 10.1590/S0102-46982009000300003

NÓVOA, A. Professores: imagem do futuro presente. Lisboa: Educa, 2009.

PARTIDO DOS TRABALHADORES. Uma escola do tamanho do Brasil. Plano de governo do candidato Luiz Inácio Lula da Silva. São Paulo: Partido dos Trabalhadores, 2002. PONGRATZ, L. La reforma educativa como estrategia gubernamental. Profesorado - revista de currículum y formación del profesorado, Granada, v. 17, n. 2, p. 141-152, maio/ago. 2013.

POPKEWITZ, T. A Reforma como Administração Social da Criança: a Globalização do Conhecimento e do Poder. In: BURBULES, N.; TORRES, C. A. (Orgs.). Globalização e educação: perspectivas críticas. Porto Alegre: Artmed, 2004. p. 107-125.

POPKEWITZ, T. PISA - números, conduta de normalização e a alquimia das disciplinas escolares. In: FAVACHO; A. M. P.; PACHECO, J. A.; SALES, S. R. (Orgs.). Currículo, conhecimento e avaliação: divergências e tensões. Curitiba: CRV, 2013. p. 89-108.

POPKEWITZ, T.; LINDBLAD, S. Estatísticas educacionais como um sistema de razão: relações entre governo da educação e inclusão e exclusão sociais. Educação \& Sociedade, v. 22, n. 75, p. 111-148, ago. 2001. DOI: 10.1590/S0101-73302001000200008

SANTOS, L. L. de C. P. Formação de professores na cultura do desempenho. Educação \& Sociedade, Campinas, v. 25, n. 89, p. 1145-1157, set./dez. 2004. DOI: 10.1590/S010173302004000400004

SCOT'T, D. Pisa, comparaciones internacionales, paradojas epistémicas. Profesorado - revista de currículum y formación del profesorado, Granada, v. 17, n. 2, p. 65-76, maio/ago. 2013.

SIBILIA, P. Redes ou paredes: a escola em tempos de dispersão. Rio de Janeiro: Contraponto, 2012.

VEIGA-NETO, A. Delírios avaliatórios: o currículo desvia para a direita ou um farol para o currículo. In: FAVACHO; A. M. P.; PACHECO, J. A.; SALES, S. R. (Orgs.). Currículo, conhecimento e avaliação: divergências e tensões. Curitiba: CRV, 2013. p. 155-175.

VIÑAO FRAGO, A. Alfabetização na sociedade e na história: vozes, palavras e textos. Porto Alegre: Artmed, 1993.

Recebido em 24/10/2014

Aceito em 08/06/2015 